\title{
COMPARISON OF SCHEMES FOR COOLING HIGH HEAT FLUX COMPONENTS IN FUSION REACTORS
}

\author{
Phani Kumar Domalapally*, Slavomir Entler
}

\author{
Centrum Výzkumu Řě̌, Řě̃ U Prahy, Czech Republic \\ * corresponding author: P_Kumar.Domalapally@cvrez.cz
}

\begin{abstract}
Some components of fusion reactors receive high heat fluxes either during startup and shutdown, or while the machine is in operation. This paper analyzes various ways of enhancing heat transfer using helium and water for cooling these high heat flux components. Conclusions are then drawn to decide on the best choice of a coolant for use in the near term and in the long term.
\end{abstract}

KEYWORDS: high heat flux components; helium cooling; water cooling; critical heat flux..

\section{INTRODUCTION}

In fusion reactors such as the International Thermonuclear Experimental Reactor (ITER) and the Demonstration Fusion Power Reactor (DEMO), the heat fluxes on the Plasma Facing Components (PFCs) such as the Divertor and the First Wall, can be of the order of 1 to $20 \mathrm{MW} / \mathrm{m}^{2}$, depending on the location 1, 2. If not properly cooled, these components will fail due to problems caused by excessive temperature. It is necessary to design an active cooling system to prevent damage to these components. The design of the active cooling system should include selecting a proper heat sink and a proper coolant. The heat sink should be selected such that it has high thermal conductivity, high mechanical resistance, compatibility with the coolant, compatibility with the armoring materials, resistance to radiation damage, adequate resources and ease of fabrication [3]. At the same time, the selected coolant should have high heat capacity, be non-toxic, safe to use, non-corrosive, chemically and electrically inert, and if possible not affected by magnetic fields. So when the final cooling system is made it should be able to provide perfect cooling in all adverse conditions, with minimum pumping power.

Based on these requirements, three different coolants have been proposed: liquid metals (e.g., K, $\mathrm{Na}, \mathrm{LiPb}$ ), helium, and water (4]. This paper discusses and analyses the advantages and disadvantages of the different coolants, and then discusses various ways of increasing the effective Heat Transfer Coefficient (HTC) of the fluids. Finally, conclusions are drawn on the basis of the details provided here.

\section{Cooling SCHemes}

As discussed in the previous section, the proposed coolants are liquid metals, helium, and water. Liquid metals are proposed as coolants because of their high thermal conductivity and high heat capacity, which enable them to accommodate high heat fluxes (HHF) with relatively low velocities. If used in two-phase flow, very low pumping speeds in turn pumping power is required. The operating life of pressurized feed pipes can be extended due to the ability of a liquid metal to absorb a huge amount of energy without producing high pressure. However, if liquid metals are used, electrically insulating coatings have to be used. Liquid metals can be chemically active, and corrosion can be a problem. In addition, magnetohydro-dynamic effects may decrease the heat transfer capability, and excessive driving force may be needed. If excessive driving force is used in a two-phase regime, there is a possibility of Critical Heat Flux (CHF) 5].

Helium cooling is very advantageous, as helium is an inert gas that is already present in the system. Tritium can easily be separated from helium, and it will not act as an additional contaminant as it is already present in the reactor. Helium is favored over water for safety reasons if liquid metal blankets are used. It offers single phase heat transfer without the possibility of CHF, and then the machine can be operated at a higher temperature, and so higher thermal efficiency can be obtained when combined with the Brayton cycle. However, helium has very low heat capacity, so in order to absorb very high heat fluxes we have to use heat transfer enhancement methods coupled with high pressures and velocities [6].

Water has several advantages, such as good heat transport properties with relatively small pumping power. Very high HTCs are associated when used in a two-phase flow regime, and water is cheaper than the other coolants. However, water is not compatible with the liquid metal tritium breeder. The low outlet temperature leads to low thermal efficiency, and this can be dangerous in the event of a leak, and a large vapor fraction may result in $\mathrm{CHF}[\underline{5}$.

Although each of the coolants has some advantages and disadvantages, preference is given to helium and water. This is because there are still several problems associated with using liquid metals as a coolant [5]. A simple channel/tube without any enhancement technique can be used for fusion applications to handle very high $\mathrm{HF}$, but in this case very high pumping speeds and pressures are required. It is therefore nec- 


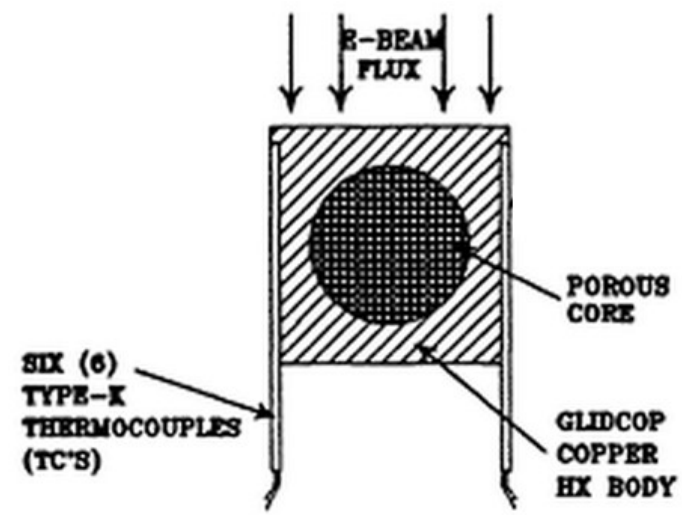

Figure 1. Porous metal (copper) heat exchanger test article [8].

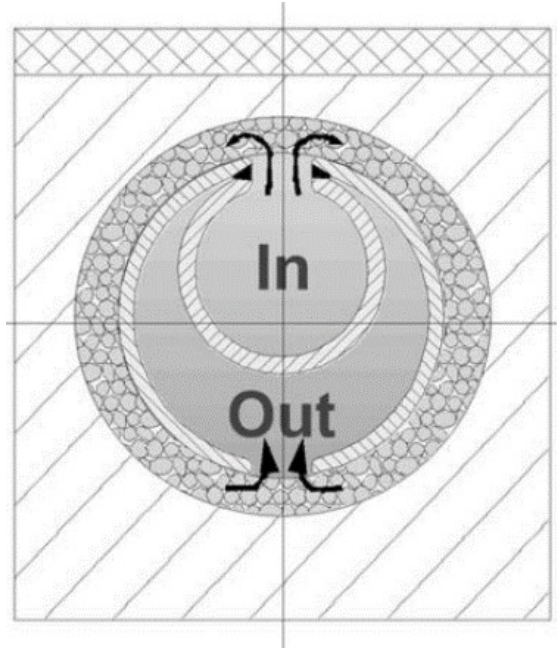

FiguRE 2. Target plate cross section of the porous medium (refractory material) concept with improved flow path design [10].

essary to use heat transfer enhancement techniques, which improve the heat transfer efficiency. In the following sections these techniques are discussed in brief.

\section{Helium cooling}

Several methods have been proposed in the literature for increasing the heat transfer capability using helium as a coolant, e.g., a porous medium or extended surfaces and jet cooling. These cooling schemes will be discussed in this section.

Porous metal exchangers provide a large surface area, which directly influences the heat transfer. The pressure drop in porous media is dependent on the porosity of the medium, and HTC is dependent on the specific surface area [7]. Several porous medium heat exchangers have been proposed in the literature, and $\mathrm{Cu}, \mathrm{W}$, Ta etc. are the porous materials that are used [8, 9]. The test article, as shown in Figure 1, is made up of dispersion strengthened copper, and the copper porous metal has been brazed in the middle. The test article was optimized parametri-

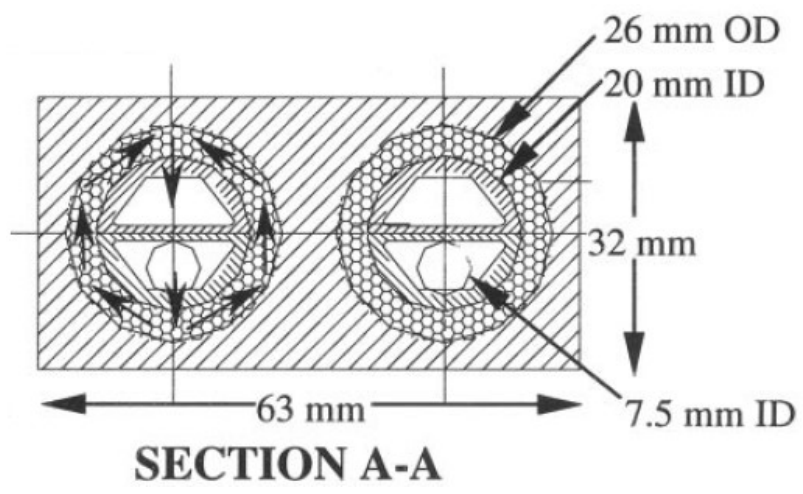

FiguRE 3. The helium divertor module is a dualchannel, circumferential flow, porous metal (oxygenfree copper) device [11.

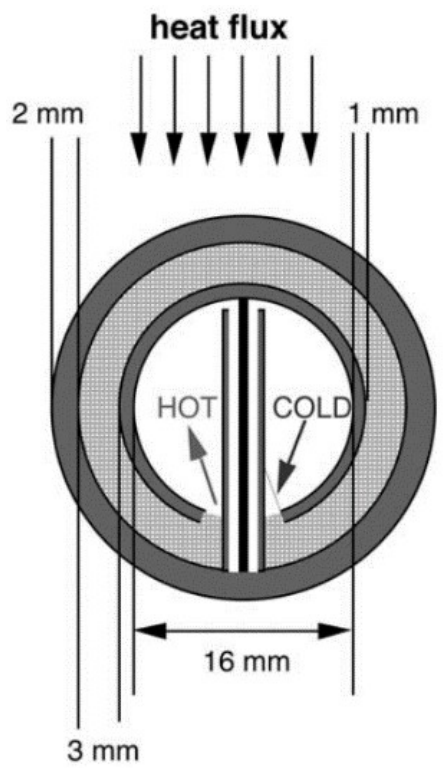

FIGURE 4. Scheme of a porous medium (refractory foam) heat exchanger [7, 12.

cally on the gas flow rate, the flow channel diameter, the spacing and depth below the surface, the particle size of the metal powder, and the system pressure, where HTCs ranging from $15-18 \mathrm{~kW} / \mathrm{m}^{2} \mathrm{C}$ were achieved when tested at the Sandia National Laboratory (SNL) 8].

Figure 2 shows an advanced version of the previous concept with the circumferential flow passage compared to the axial inlet and exhaust passages reducing the pressure drop [9, 10]. This concept has two tubes surrounded by a porous medium. Figure 3 shows a dual channel circumferential flow porous metal design. The objective of this design was to mitigate the flow bypass while still maintaining low pressure drops. The porous medium was made up of oxygenfree copper spheres brazed to the outer shell forming $\sim 40 \%$ porosity. The test article was able to withstand $29.5 \mathrm{MW} / \mathrm{m}^{2}$ with helium flowing at $20 \mathrm{~g} / \mathrm{s}$ and $4 \mathrm{MPa}$ [11.

The design as shown in Figure 4 also allows for 


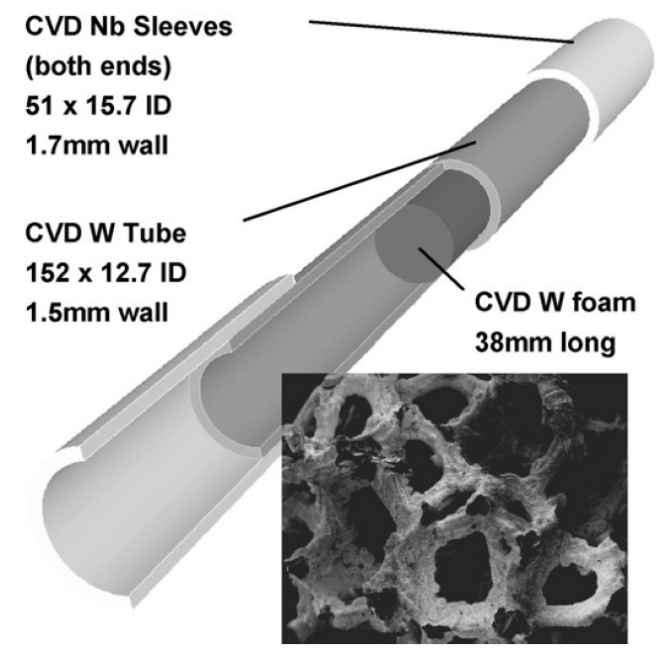

Figure 5. Sketch of the CVD mockup. The inset is an SEM photo of tungsten porous foam [6].

shorter flow paths than the axial flow by allowing circumferential flow. In this concept, refractory foams are used whose porosity and specific surface area can be optimized. The porous foam can be manufactured using tungsten (W), which is of particular interest in fusion applications. In order to accommodate $5 \mathrm{MW} / \mathrm{m}^{2}$ heat flux and maintain the temperature of the tungsten below $1400^{\circ} \mathrm{C}$, the required velocities are $11,15,53 \mathrm{~m} / \mathrm{s}$ for porosity values of $50 \%, 80 \%$ and $95 \%$, with pressure drops of $0.32,0.07$ and 0.07 , respectively. Using this concept it is also possible to accommodate $30 \mathrm{MW} / \mathrm{m}^{2}$, but in order to keep the surface temperature below $1400^{\circ} \mathrm{C}$, it is necessary to have $120 \mathrm{~m} / \mathrm{s}$ velocity with $80 \%$ porosity, which leads to a pressure drop of $2 \mathrm{MPa}$ [7, 12.

The tungsten foam in the tube concept is shown in Figure 5, where the Chemical Vapor Deposition (CVD) technique is used for forming the $\mathrm{W}$ foam. This has an advantage over a packed bed of balls or irregular solids, as the relatively large interconnected free volume around the ligaments is available for helium flow, which considerably reduces the pressure drop. Articles made using this concept were tested at SNL, where they were able to remove $22.4 \mathrm{MW} / \mathrm{m}^{2}$ with He flowing at $27 \mathrm{~g} / \mathrm{s}$, at $4 \mathrm{MPa}$. The tests also showed that a linear pressure drop of $1.87 \mathrm{MPa} / \mathrm{m}$ is obtained with helium flow at $4 \mathrm{MPa}$ and $24.8 \mathrm{~g} / \mathrm{s}$ [6]. The Short Flow Path Foam-In-Tube (SOFIT) design (Figure 6) uses axial flow from an inlet tube towards the high heat flux surface through a slot, where helium flows circumferentially through a foam from a $2 \mathrm{~mm}$ wide slot separating the inlet and outlet plenums. As the flow path through the foam is very short, the pressure drop is much less than the other pressure drops. This device is able to handle $10 \mathrm{MW} / \mathrm{m}^{2}$ before reaching $800^{\circ} \mathrm{C}$ on the surface with $28 \mathrm{~g} / \mathrm{s}$ of helium at $4 \mathrm{MPa}$ and an inlet temperature of $40^{\circ} \mathrm{C}[13$.

Extended surfaces increase the effective HTC by the following mechanisms: a reduced flow area in-
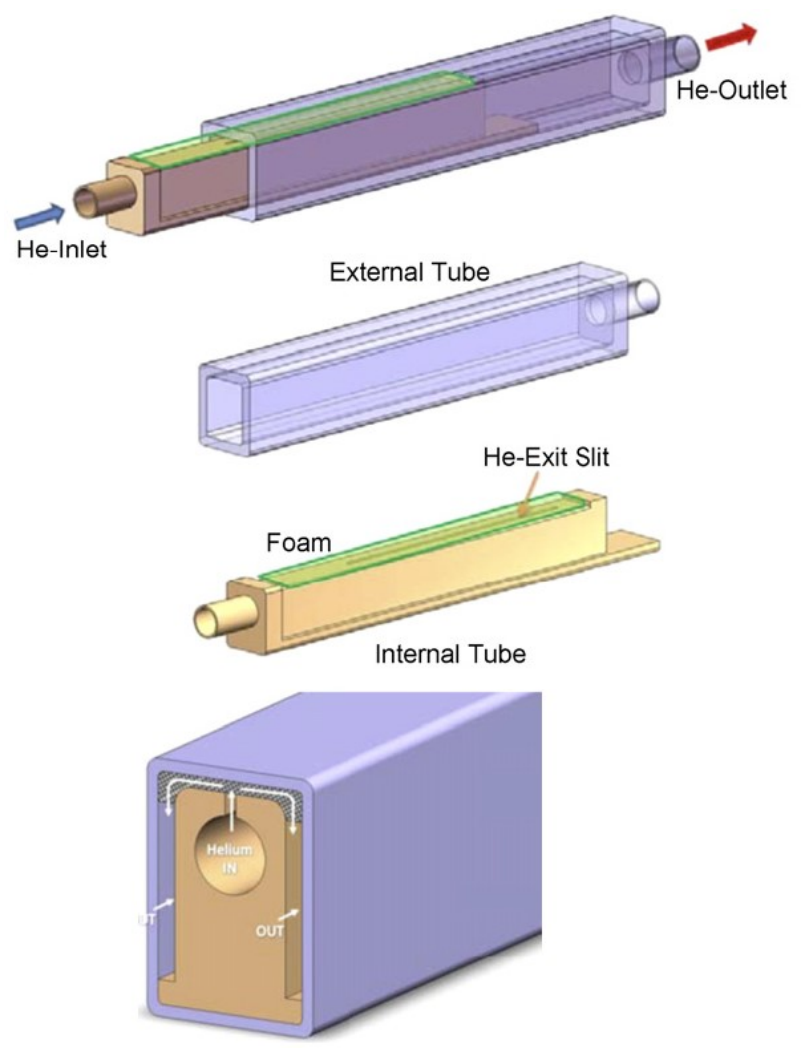

Figure 6. Assembly drawing of the Short Flow Path Foam-In-Tube (SOFIT) design [13].

creases the flow velocity, the hydraulic diameter is smaller, and finally the heat transfer area is increased; extended surfaces be provided by pin fins, by $2 \mathrm{D}$ or $3 \mathrm{D}$ surface roughness, or by using ribs. Table 1 gives a general idea about how various heat transfer enhancement methods contribute to an increase in HTC and in the friction factor (FF) over a smooth tube [14. 2D and $3 \mathrm{D}$ roughness increases the HTC by breaking the laminar boundary layer near the wall [14. A swirl rod insert (SRI) uses a rod with fins in place of a twisted tape. This reduces the hydraulic diameter and produces higher effective flow velocities. The increase in HTC and FF when using this method can be found in Table 1. A combination of SRI and 2D roughness is very effective, and tests conducted at SNL showed that it can easily withstand $5 \mathrm{MW} / \mathrm{m}^{2}$ [14].

Using pin fins increases the effective HTC to a very high value, but the increase depends on the type of coolant, the material, and also the geometry orientation of the fins. Figure 7 shows a test module fabricated using dispersion strengthened copper, designed by General Atomics and tested at SNL. The test results show that the module was able to withstand $10 \mathrm{MW} / \mathrm{m}^{2}$ at $4 \mathrm{MPa}$ and $22 \mathrm{~g} / \mathrm{s}$ flow rate without any damage, and the pumping power required was $<1 \%$ of the total power removed [15].

Figure 8 shows the scheme of the annular flow square ribbed channel, which is used to increase the turbulent heat transfer. Square ribbed channels can provide a 200-300 \% increase in HTC in comparison with smooth 


\begin{tabular}{lcc}
\hline & $\begin{array}{c}\text { HTC over } \\
\text { smooth }\end{array}$ & $\begin{array}{c}\text { FF over } \\
\text { smooth }\end{array}$ \\
\hline Microfins
\end{tabular}

TABLE 1. Heat transfer enhancement methods [14].

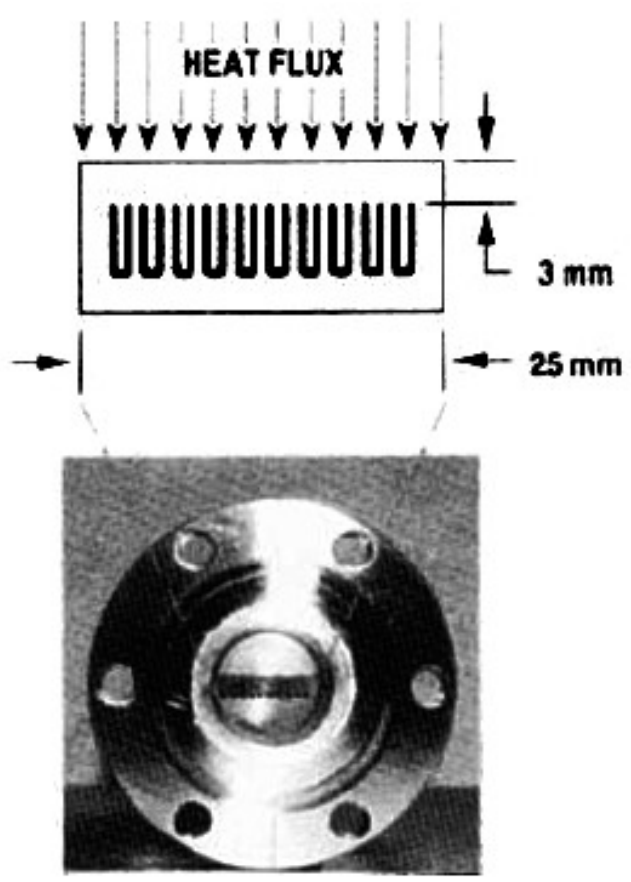

Figure 7. Helium-cooled Divertor module [15.

channels. For a pitch-to-height ratio of 10 and with a Reynolds number of 65000 the channel was able to remove $1.5 \mathrm{MW} / \mathrm{m}^{2}$ heat flux 16 .

The concept of a helium-cooled modular pin array (HEMP) is shown in Figure 9. A modular design instead of large plate structures is advantageous for thermal stress, when used in designing large structures such as the divertor. The HEMP design consists of $\mathrm{W}$ tiles brazed in to a thimble (finger) made of molybdenum alloy (TZM). The fingers are inserted into a front plate made of TZM. In the study carried out by E. Diegele et al. [17, TZM was assumed to be the structural material, but RAFM-ODS steels are also used as the structural material of the back plate. The inlet temperature of the helium gas is $620^{\circ} \mathrm{C}$ at $10 \mathrm{MPa}$. The inlet temperature was dictated by the ductile brittle transition temperature of the materials. To improve the heat convection at the top of the finger, a plate is inserted (by brazing) with a pin fin array,

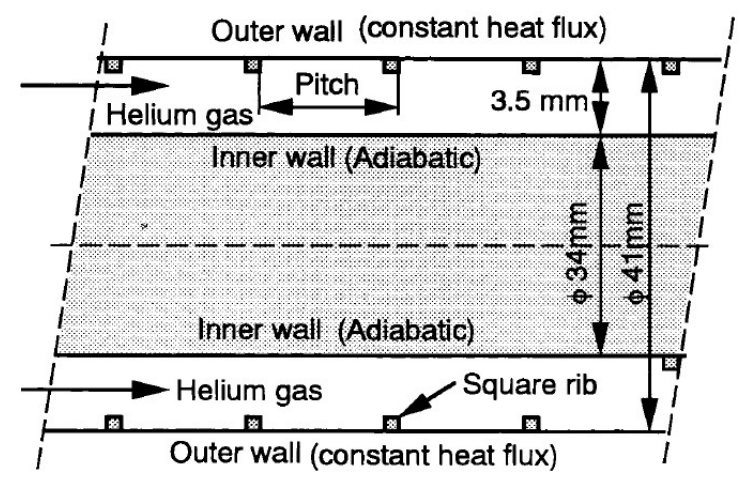

FIGURE 8. Illustration of a square-ribbed annular channel [16].

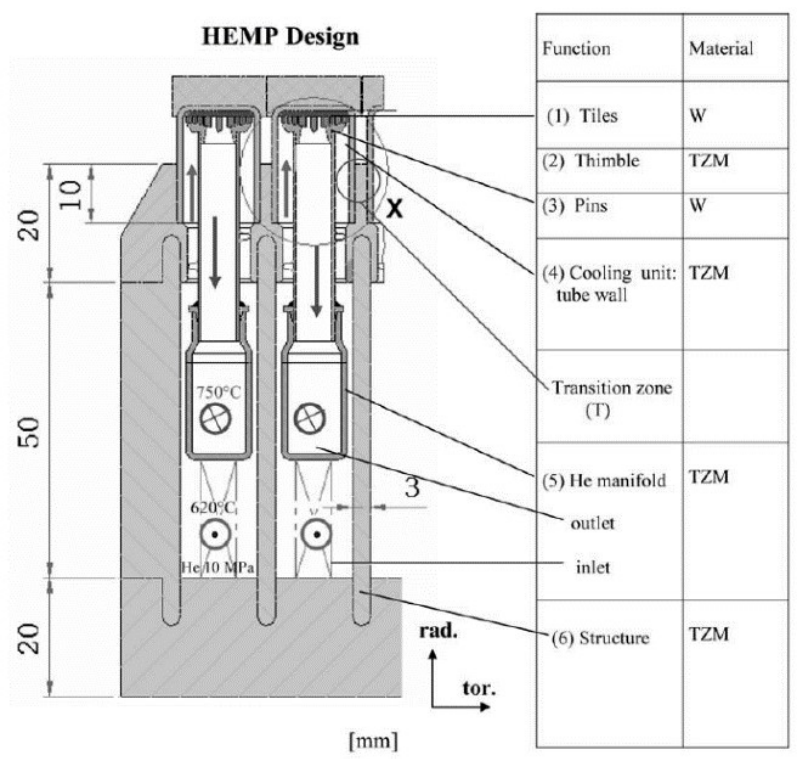

FiguRE 9. He-cooled modular divertor design with pin arrays (HEMP) [17.

which dictates the performance of the design. This concept has the potential to remove $15 \mathrm{MW} / \mathrm{m} 2$ heat flux, and an HTC excess of $60 \mathrm{~kW} / \mathrm{m}^{2} \mathrm{~K}$ is estimated, where the pumping power is $<5 \%$ of the thermal power [17].

Jet impingement cooling is an effective technique for achieving very high HTCs with much lower pressure drops than for other techniques. When helium at high pressure $(\sim 10 \mathrm{MPa})$ leaves the hole or slot and this jet hits the surface that is being exposed to $\mathrm{HHF}$, the outlet velocity of the jet is so high that there is immediately turbulent flow, resulting in increased local turbulent mixing and very high HTCs [18. Various techniques have been proposed for achieving this, namely an impinging jet with particulate addition, Helium-Cooled Modular Jet cooling (HEMJ), HeliumCooled Modular Slot array cooling (HEMS), T-tube design, Plate type design, and integrated design.

The addition of $\mathrm{SiC}$ particles to the helium impinging jet is expected to give HTC up to $20000 \mathrm{~W} / \mathrm{m}^{2} \mathrm{~K}$, which can handle heat fluxes of the order of $10 \mathrm{MW} / \mathrm{m}^{2}$ [19. 


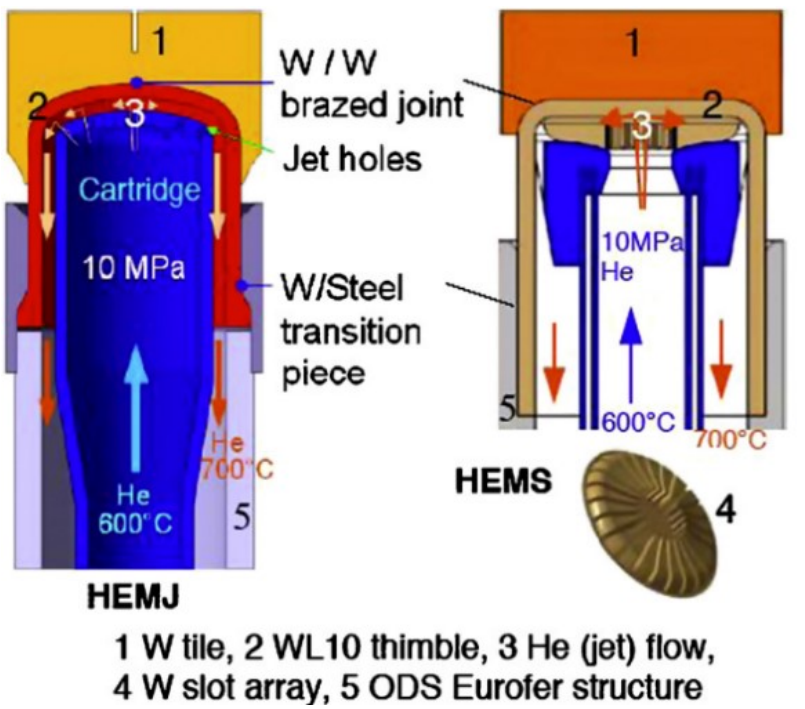

Figure 10. Schematics of HEMJ and HEMS Divertor finger concepts 20].

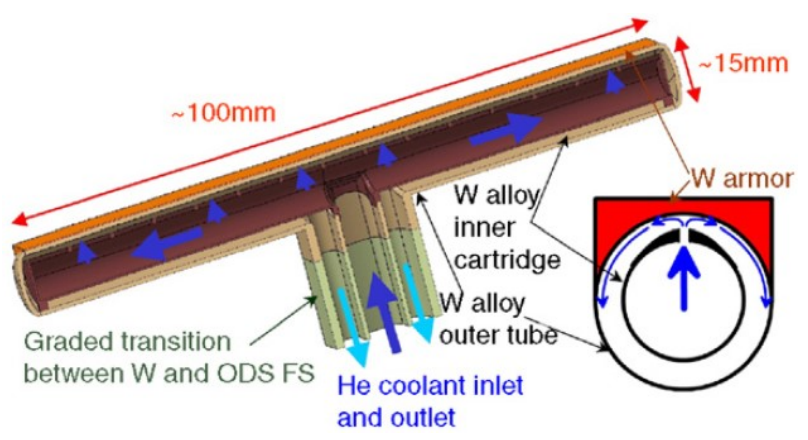

Figure 11. Cross-section of the mid-size T-tube ARIES Divertor concept 18.

The finger concept or the modular concept (HEMJ, HEMS) is designed to minimize the thermal stresses and accommodate high heat fluxes. Figure 10 illustrates these concepts. These configurations include small hexagonal armor tiles made of $\mathrm{W}$, which is brazed to a $\mathrm{W}$ alloy thimble (on which jet impingement occurs and cools the surface of the plasma facing). The cooling unit uses helium at $10 \mathrm{MPa}$ and $600 / 700^{\circ} \mathrm{C}$ as the inlet temperature [20]. This cooling structure is joined to the remaining body using some transition pieces. A detailed discussion about this can be found elsewhere. These modular concepts are designed to withstand heat fluxes of at least $10 \mathrm{MW} / \mathrm{m}^{2}$. The experiments showed that the HEMJ concept can handle higher heat fluxes with lower pressure drop than the HEMS concept 21.

The T-tube is a mid-size concept in comparison with the modular and plate type concepts. This concept is illustrated in Figure 11, where it is quoted along with its dimensions. On the plasma facing side there is $\mathrm{W}$ castellated armoring, which is joined to the $\mathrm{W}$ alloy outer tube. Helium gas impinges on to this from the W alloy inner tube through a thin slot that is cut into this tube. These two W alloy tubes can be attached to the background structure through some transition

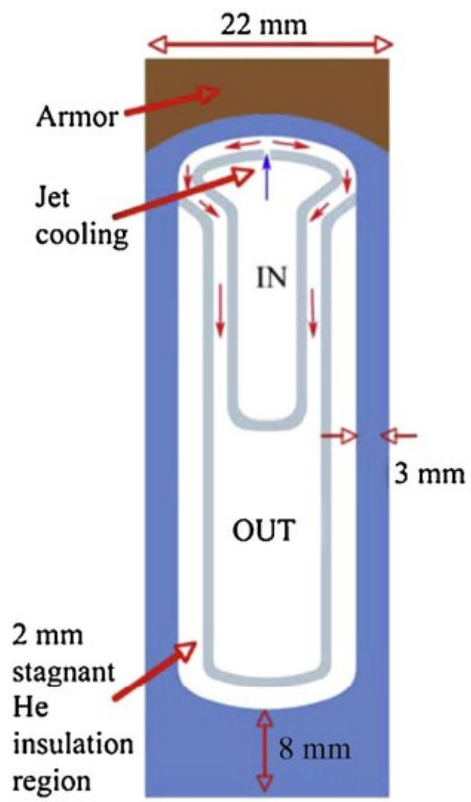

Figure 12. Cross-section of a unit cell, and a drawing of the Divertor plate module 13 .

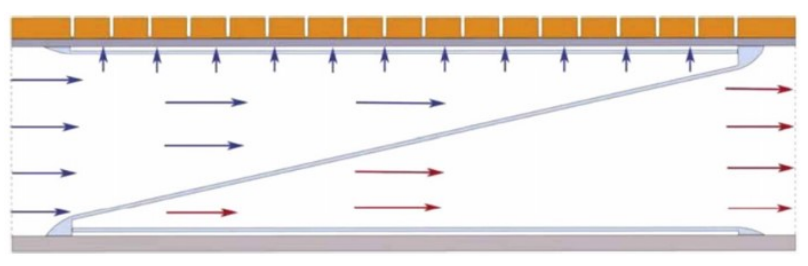

FiguRE 13. Longitudinal section through the target plate channel 13 .

pieces to the base structure made of steel to reduce the thermal stresses. This heat sink can accommodate heat fluxes in excess of $10 \mathrm{MW} / \mathrm{m}^{2}[18$. The onlet conditions are same as for the HEMJ concept.

The cross and longitudinal sections of plate type divertors are shown in Figure 12. Heat sinks of this size can minimize the number of units that are used, thanks to their large size. The plate is made of $\mathrm{W}$-alloy with castellated $\mathrm{W}$ armoring. The inlet and outlet sections are tapered in order to obtain a uniform velocity distribution. This concept can accommodate heat fluxes up to $10 \mathrm{MW} / \mathrm{m}^{2}$, with a helium inlet temperature of $\sim 600 / 700{ }^{\circ} \mathrm{C}$ at $10 \mathrm{MPa}$ [13.

Table 2 compares the three jet impingement concepts introduced above for a Divertor area of 150 $\mathrm{m} 2$.

It is known that the resulting heat flux footprint on the divertor is Gaussian-shaped, so only a part of the divertor will see high heat fluxes. In order to minimize the number of parts and increase the reliability of the joints, the integrated units are designed as shown in Figure 14. In this design, finger units are used when the expected heat fluxes are about $10 \mathrm{MW} / \mathrm{m}^{2}$, and a plate type design is used when the expected heat fluxes are lower, thus optimizing the overall design [20].

The concept for cooling the coolant is presented in 


\begin{tabular}{lccc}
\hline Divertor concept & $\begin{array}{c}\text { Unit characteristic } \\
\text { dimensions }\end{array}$ & $\begin{array}{c}\text { Number of units } \\
\text { per a typical tokamak }\end{array}$ & $\begin{array}{c}\text { Allowable incident } \\
\text { heat flux }\left(\mathrm{MW} / \mathrm{m}^{2}\right)\end{array}$ \\
\hline Finger & $1.5 \mathrm{~cm}$ in diameter & $\sim 535000$ & $>12$ \\
T-tube & $10 \times 1.5 \mathrm{~cm}$ & $\sim 110000$ & $\sim 10-12$ \\
Plate & $100 \times 200 \mathrm{~cm}$ & $\sim 750$ & $\sim 8-10$ \\
\hline
\end{tabular}

TABLE 2. A comparison of various divertor concepts for a tokomak with an assumed divertor area of $150 \mathrm{~m} 2$ [13].

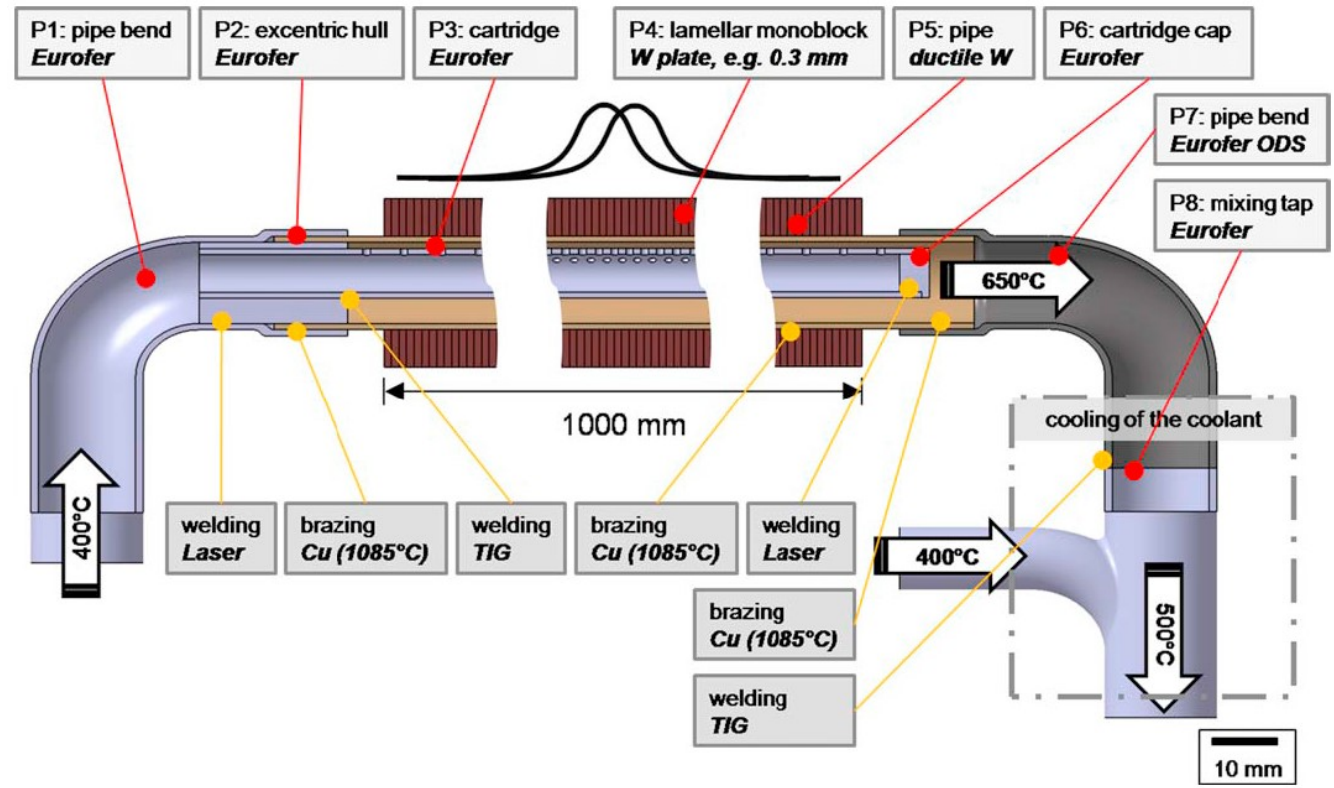

Figure 15. Helium-cooled divertor for DEMO (cooling of the coolant) 4].
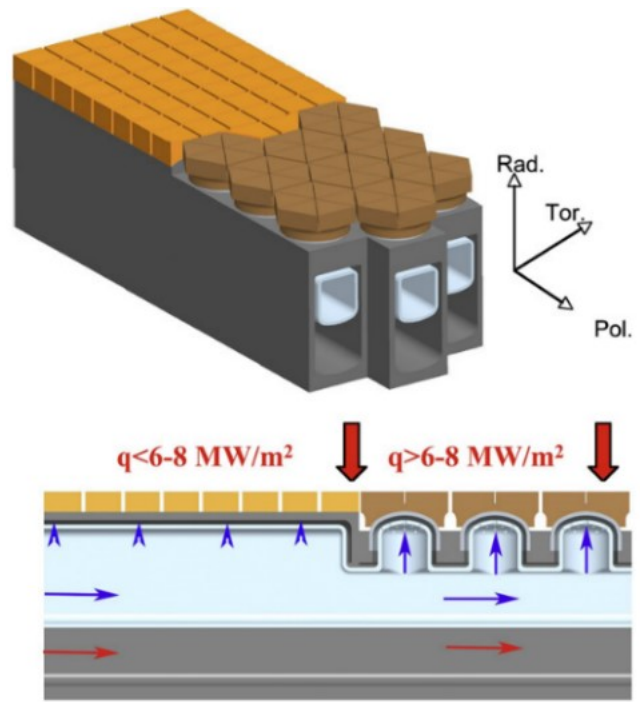

FiguRE 14. Integrated plate + finger unit 20.

Figure 15. which is designed to use cheaper Eurofer steel as much as possible, rather than costlier Eurofer ODS steel, as the outlet temperature for the concepts discussed above will be greater than $650^{\circ} \mathrm{C}$. This is achieved by using a mixing tap at the outlet of the heated region with helium gas coming at $400^{\circ} \mathrm{C}$, which can then be adjusted to a temperature of $550^{\circ} \mathrm{C}$, so that Eurofer can be used there. In this concept, in the region where high heat fluxes are estimated to occur, drillings are made in the cartridge to use the jet impinging phenomenon [4].

\section{WATER COOLING}

Water cooling gives very high HTCs when it is operated in the subcooled boiling regime, and stays below the CHF limit. Details about the boiling phenomenon can be found elsewhere [22. In the literature, several cooling techniques have been developed to increase the CHF limit, such as swirl tubes, Hypervapotrons, screw tubes, etc. In the fusion community, three design options are available when water is used as a coolant. These three options, based on bonding the plasma facing component to the heat sink [3], are the flat tile, saddle tile and mono block designs, which are discussed in 3. Here we will focus on techniques for improving heat transfer.

Adding ice particulates to the water greatly increases the heat transfer. The heat transfer and CHF are increased because inlet subcooling is increased to its maximum value. This is because the inlet temperature is at the ice melting point, thus maximizing the rise in the subcooling temperature. This allows HHF through ice melting to an extent dependent on the latent heat of fusion of ice and on the ice particulate mass flow fraction. 


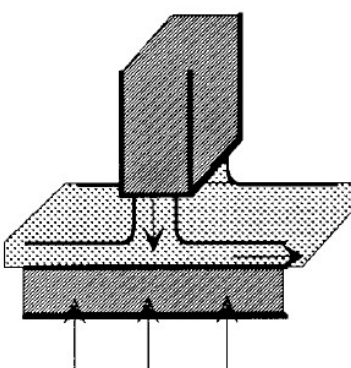

(a) Heat Flux

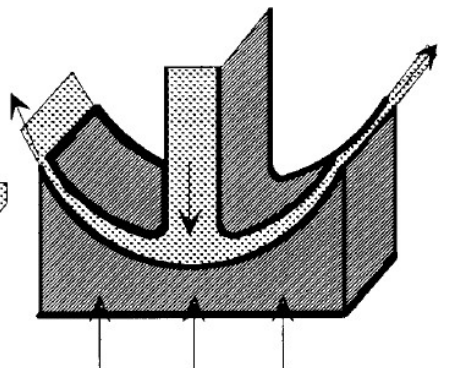

(b) Heat Flux
FigURE 16. Various systems for impinging planar jet cooling: (a) a free jet on a flat surface. (b) a confined jet on a curved surface [25].

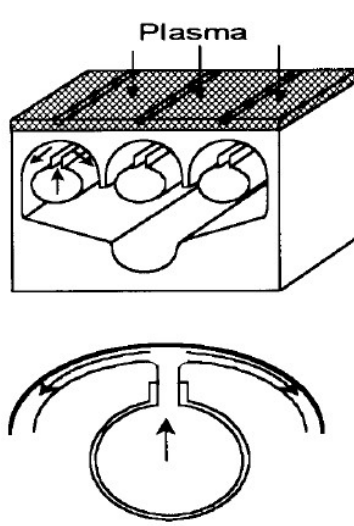

Detail of Free Jet

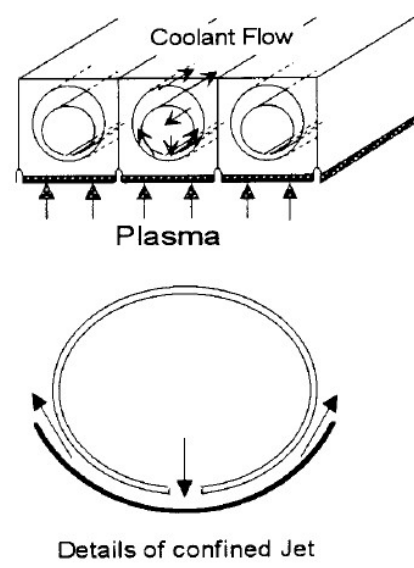

Details of confined Jet
Figure 17. Cooling the divertor by jet cooling 25$]$.

Tests that were conducted show that for water pressure of 2 bar and mass flow of $15000 \mathrm{~kg} / \mathrm{m}^{2}$, through a $1 \mathrm{~cm}$ pipe with an ice fraction of $30 \%$, if complete ice meltdown occurs, it can easily accommodate $20 \mathrm{MW} / \mathrm{m}^{2}$ heat flux 23 .

Jet impingement using water is another way to increase CHF. Figure 16 shows various impinging planar jet cooling methods. If jet cooling is used on a flat surface, very high $\mathrm{CHF}$ is obtained in the limited central region right under the jet nozzle, and CHF decreases abruptly in the region away from the center. This drawback is overcome by a jet on a curved heated surface, as shown in Figure 16(b). Using this technique, a maximum $\mathrm{CHF}$ of $38 \mathrm{MW} / \mathrm{m}^{2}$ was obtained locally under conditions of jet velocity $\mathrm{V}=$ $14.6 \mathrm{~m} / \mathrm{s}, T_{\text {sub }}=80 \mathrm{~K}$, on a curved cooling surface with radius of curvature $\mathrm{R}=24.5 \mathrm{~cm}[24$. Figure 17 shows various divertor designs using jet cooling, namely free jet and confined jet techniques. The confined planar jet can construct a compact cooling system so as to fit the heat flux distribution more suitably, by changing the flow velocity, and can operate under elevated pressure. Free planar jet cooling has the advantage of keeping the pressure drop in the cooling system small [25].

Porous media can be used in various ways for increasing heat transfer. Mechanically pumped porous media heat exchangers, capillary pumped exchangers

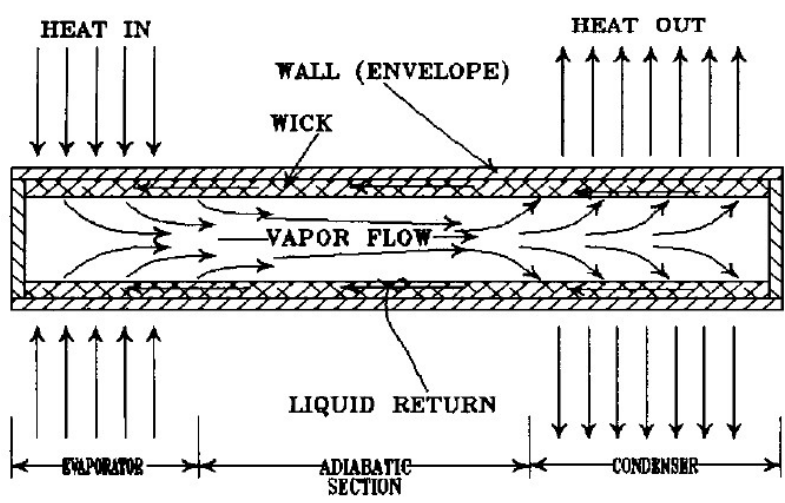

Figure 18. Heat and working fluid flow in a heat pipe [26].

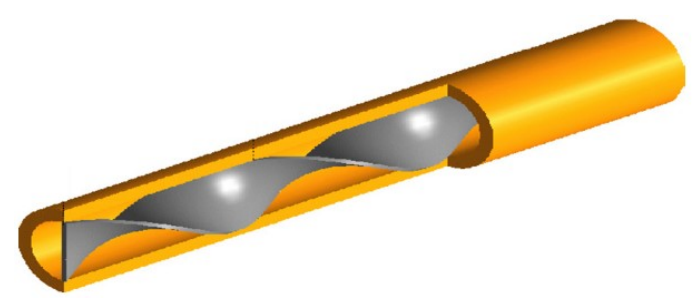

Figure 19. Swirl Tube 29].

(heat pipes) and porous coatings are discussed in the literature. Pumped single phase porous media heat exchangers using water, which can remove heat fluxes in the range of $100 \mathrm{MW} / \mathrm{m}^{2}$, were tested at SNL [26]. There are several reasons for preferring heat pipes (Figure 18) for removing heat. Heat pipes can be designed to work against gravity. They are passive, i.e. they require no mechanical pump to function. They also require only a relatively small amount of working fluid, so failure of a heat pipe will only allow a relatively small amount of working fluid to leak out. They can also be used to control heat removal at a uniform or constant temperature, or to spread a high heat flux to a larger area to allow heat removal by conventional techniques. Water heat pipes were evaluated for cooling the Faraday shield that protects the radio frequency $(\mathrm{RF})$ antennae used for plasma heating. Tests on these devices have shown their ability to absorb localized heat fluxes in excess of $10 \mathrm{MW} / \mathrm{m}^{2}[26]$.

A porous coating is another way to enhance CHF. It is interesting because it increases the CHF by approximately $40-60 \%$ over a smooth channel, but the pressure drop is almost of the same order as the pressure drop of a smooth channel [27]. The tests conducted at SNL showed that $\mathrm{ICHF}=24.5 \mathrm{MW} / \mathrm{m}^{2}$ is obtained with water flowing at $4 \mathrm{MPa}, 100^{\circ} \mathrm{C}, 10 \mathrm{~m} / \mathrm{s}$, with a pressure drop of $0.19 \mathrm{MPa} / \mathrm{m}$ 27. Erosion and corrosion of the porous coating has kept this method from wide acceptance [28].

A swirl tube uses a tape which is twisted and inserted into a circular tube, as shown in Figure 19 The increase in $\mathrm{CHF}$ is obtained due to turbulence and the superimposed vortex motion (swirl flow), causing a 


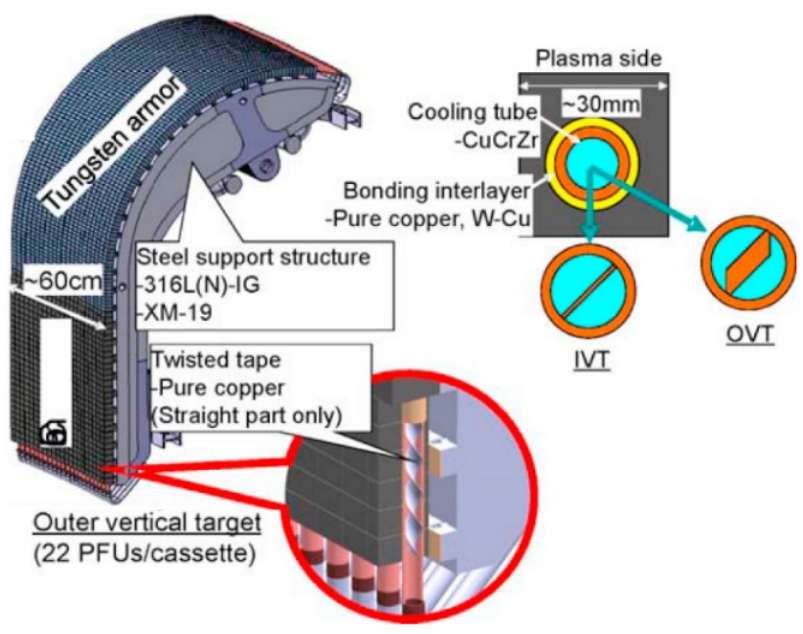

FiguRE 20. Scheme of the outer vertical target 30].

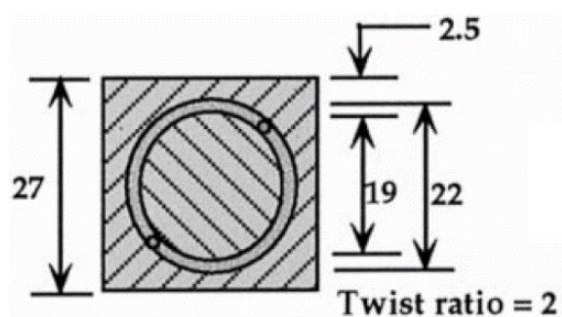

Figure 21. Scheme of an annular flow tube (a swirl tape with a solid center piece) [27.

thinner boundary layer and consequently resulting in a high heat transfer coefficient and Nusselt number, due to repeated changes in the twisted tape geometry [29]. An increase in $\mathrm{CHF}$ values by $>50 \%$ compared to the values for smooth tubes have been obtained using a swirl tube in various experiments. Several experiments have been conducted internationally on a swirl tube as a CHF enhancer, and it is the reference design for cooling the vertical target of the divertor at ITER, with a monoblock configuration [30, where it has been shown that swirl tubes can easily accommodate a $20 \mathrm{MW} / \mathrm{m}^{2}$ heat flux 30,31 .

Figure 20 shows the scheme of the ITER outer vertical target (OVT), with the location of the swirl tubes. The same figure shows the cross section of the tubes used for the inner vertical target (IVT) and for the outer vertical target (OVT). The cross section of the twisted tape used for OVT has the form of a parallelogram with the sharp edges chopped off. Its sheet thickness is thicker than that used for IVT, in order to sustain critical heat flux performance equivalent to that of IVT under a lower coolant flow rate than IVT [30.

The scheme of an annular flow swirl tube is presented in Figure 21. It is similar to a swirl tube, except that it has a solid center piece. The annular swirl is not preferred, as it provides relatively little data. Its CHF is no better than the CHF for the swirl tape, but there is a higher pressure drop for a given flow rate [27.

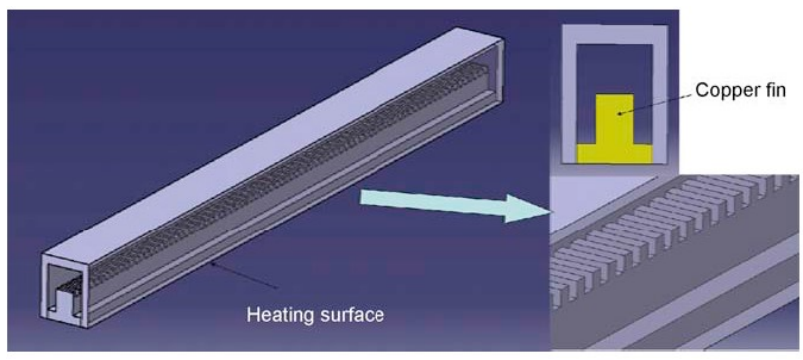

FiguRE 22. Hypervapotron module configuration [34].
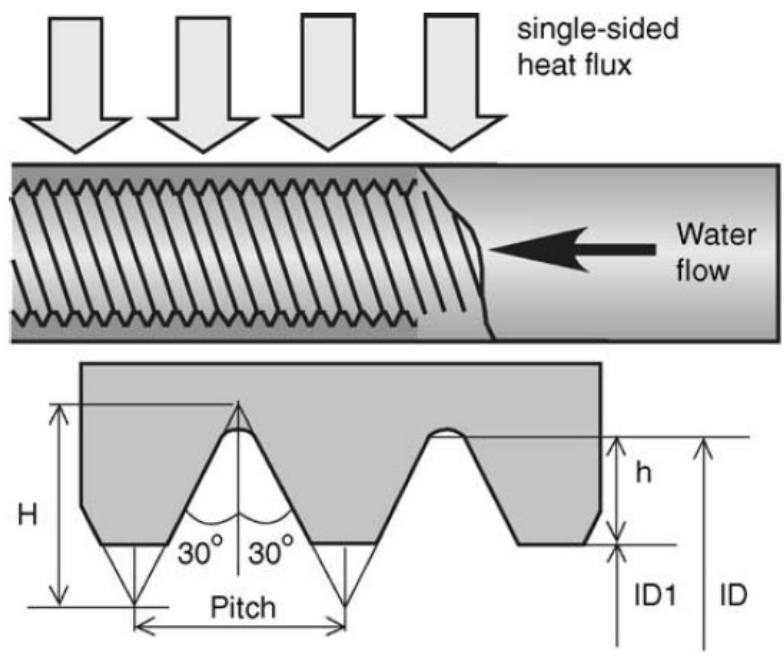

\begin{tabular}{lccccc}
\hline Name & Pitch & $\mathrm{H}$ & ID & ID1 & $\mathrm{h}$ \\
\hline M10xP1.5 & 1.5 & 1.23 & 10 & 8.38 & 0.81
\end{tabular}

Figure 23. Schematic view of a screw tube made of $\mathrm{F} 82 \mathrm{H}$ and heating condition [36].

The hypervapotron consists of fins which are placed perpendicular to the direction of flow, and has slots at each end of the fins parallel to the direction of flow, as shown in Figure 22 When sufficient heat flux is applied to the wall which is in contact with the Hypervapotron fins, the liquid between the two adjacent fins boils. When the slot between the fins is full of steam, it rapidly condenses in the bulk subcooled liquid. The slots are therefore empty, and are ready to be replenished with fresh cold liquid. This phenomenon of continuous boiling and condensation between the slots increases the critical heat flux 32 . The CHF values were $>50 \%$ higher than for smooth tubes when the Hypervapotron was used in various experiments. It can easily withstand $20 \mathrm{MW} / \mathrm{m}^{2}$, as has been verified by several experiments [33, 34]. It used in the dome liner and also in some places in first wall at ITER to deal with heat fluxes $\sim 5 \mathrm{MW} / \mathrm{m}^{2}$. For an equivalent flow, the Hypervapotron has the highest CHF limit, and the pressure drop is also lower than for swirl tubes [27, 34].

A comparison made by Smid et al. 35 proved that Hypervapotron has a better thermal hydraulic performance than a swirl tube, but that the swirl 
tube has a better thermomechanical performance. In order to gain the advantages of the performance of both Hypervapotron (from the thermohydraulic side) and the swirl tube (from thermomechanical side), the definition of the best concept could be a combination of the two concepts: a circular channel with helical fins (which is just a screw tube). A screw tube is a cooling tube with a helical triangular fin on its inner cooling surface, as shown in Figure 23 The nut-like inner surface can work as a combination of enlarging the heat transfer area and a turbulence promoter of cooling water near the surface to enhance the heat transfer [36. Heat fluxes in excess of $20 \mathrm{MW} / \mathrm{m}^{2}$ can be accommodated using a heat sink made with this geometry. It has been reported that a screw tube made of pure $\mathrm{Cu}$ achieves twice as much heat removal as a smooth tube 36 . It was assumed that the screw would act as a crack initiator, but experiments carried out at JAERI found that this is not what happens. However, further investigation under cyclic loading is needed [37.

\section{Conclusions}

Various cooling schemes relevant for fusion applications have been presented, focusing on the use of helium and water as working fluids for cooling $\mathrm{HHF}$ components. Advantages and disadvantages of various cooling schemes have been presented.

One of the main problems encountered today comes from the materials used for PFCs and heat sinks. The properties of these materials can differ, leading to thermal stresses and to the failure of a component. However, an optimized thermohydraulic design not only results in safe operation of the reactor but also minimizes the PFC temperatures, the coolant flow and the pumping power requirements, while extending the life of the reactor.

It has been mentioned that if simple channels are used (without turbulence enhancers) very high velocities and pressures are required. This would not be economical, so turbulence enhancers are essential and should be used for cooling in order to deal with HHF. The main criteria in choosing a particular fluid and turbulence enhancer are the cooling capacity of the fluid and the pressure drop (which in turn decides the pumping speed).

Helium cooling is very advantageous because of its safety features and its operating temperatures. It can be directly combined with the Brayton cycle to produce very high thermal efficiency. Among the heat transfer enhancers, jet cooling has undergone more experiments and has received much attention as it can deal with heat fluxes of the order of $10 \mathrm{MW} / \mathrm{m}^{2}$ with lower pressure drops. The heat flux footprint on the divertor is Gaussian in shape, so the integrated plate and finger type cooling system is very advantageous as the number of units can be decreased. However, the SOFIT and HEMP concepts need extensive study, as these concepts have very high potential for removing
HHF. In addition, there is a need for further research to find suitable materials. Helium cooling will used in future fusion reactors, as helium is a very attractive coolant for achieving greater plant efficiency.

Water cooling is attractive, as it has been used for a long time for cooling various components in various fields, and there is a very large database of experiments to be drawn on. At the same time, water can handle very high heat fluxes with lower pressures and velocities than helium. The main caveat with a water cooling system is the CHF limit, and several ways of increasing this limit have been mentioned here. The swirl tube with a monoblock design is used for HHF applications at ITER to handle very high heat fluxes of the order of $10-20 \mathrm{MW} / \mathrm{m}^{2}$, as can be seen in the vertical target of the divertor. Hypervapotron will be used to handle heat fluxes of the order of $5 \mathrm{MW} / \mathrm{m}^{2}$, as can be seen in the dome of the divertor and as the Enhanced Flux design of the first wall. The screw tube has the advantages of both the swirl tube and Hypervapotron. Experiments conducted by a Japanese team have shown that the screw tube has better cooling capability than the swirl tube, but the experimental database on this scheme is limited in size, and needs to be improved before the screw tube is ready for use in future reactors.

For the near term, water cooling is very attractive for fusion reactors. However, further research and development can make helium cooling advantageous in the longer term.

\section{REFERENCES}

[1] Raffray, A.R., Merola, M.: Overview of the design and R\&D of the ITER blanket system, Fusion Engineering and Design Volume, 87 (5-6), 2012, p. 769-776.

[2] Norajitra, P., et al.: Progress of He-cooled Divertor development for DEMO, Fusion Engineering and Design, 86 (9-11), 2011, p. 1656-1659.

[3] Chappuis, Ph., et al.: Possible Divertor solutions for a fusion reactor. Part 2. Technical aspects of a possible Divertor, Fusion Engineering and Design, 36, 1997, p. 109-117.

[4] Reiser, J., Rieth, M.: Optimization and limitations of known DEMO Divertor concepts, Fusion Engineering and Design, 87 (5-6), 2012, p.718-721.

[5] Dobran, F.: Fusion energy conversion in magnetically confined plasma reactors, Progress in Nuclear Energy, 60, 2012, p.89-116.

[6] Youchison, D.L., et al.: High heat flux testing of a helium-cooled tungsten tube with porous foam, Fusion Engineering and Design, 82 (15-24), 2007, p.1854-1860.

[7] Raffray, A.R., Pulsifer, J.E.: MERLOT: a model for flow and heat transfer through porous media for high heat flux applications, Fusion Engineering and Design, 65 (1), 2003, p.57-76.

[8] Rosenfeld, J.H., et al.: Cooling of plasma facing components using helium-cooled porous metal heat exchangers, Fusion technology, 27 (14), 1994, p.255-258. 
[9] Wong, C.P.C., et al.: Helium-cooled refractory alloys first wall and blanket evaluation, Fusion Engineering and Design, 49-50, 2000, p.709-717.

[10] Hermsmeyer, S., Malang, S.: Gas-cooled high performance Divertor for a power plant, Fusion Engineering and Design, 61-62, 2002, p.197-202.

[11] Youchison, D.L., et.al.: Thermal performance and flow instabilities in a multi-channel, helium-cooled, porous metal Divertor module, Fusion Engineering and Design, 49-50, 2000, p.407-415.

[12] Pulsifer, J.E., Raffray, A.R..: Structured porous media for high heat flux fusion applications, Proceedings of the 19th IEEE/NPSS Symposium on Fusion Engineering, 2002, p.352-355.

[13] Tillack, M.S. , et al.: Recent US activities on advanced He-cooled W-alloy Divertor concepts for fusion power plants, Fusion Engineering and Design, 86,(1), 2011, p.71-98.

[14] Baxi, C.B., Wong, C.P.C.: Review of helium cooling for fusion reactor applications, Fusion Engineering and Design, 51-52, 2000, p.319-324.

[15] Baxi, C.B.: Evaluation of helium cooling for fusion Divertors, Fusion Engineering and Design, 25, (1-3), 1994, p.263-271.

[16] Takase, K.: Forced convective heat transfer in square-ribbed coolant channels with helium gas for fusion power reactors, Fusion Engineering and Design, 49-50, 2000, p.349-354.

[17] Diegele, E., et.al.: Modular He-cooled Divertor for power plant application, Fusion Engineering and Design, 66-68, 2003, p.383-387.

[18] Ihli, T., et.al.: Design and performance study of the helium-cooled T-tube Divertor concept, Fusion Engineering and Design, 82 (3), 2007, p.249-264.

[19] Yamazaki, S. et.al.: Design study of helium-solid suspension cooled blanket and divertor plate for a tokamak power reactor, Fusion Engineering and Design, 25 (1-3), 1994, p.227-238.

[20] Raffray, A.R., Malang, S., Wang, X.: Optimizing the overall configuration of a He-cooled W-alloy Divertor for a power plant, Fusion Engineering and Design, 84 (7-11), 2009, p.1553-1557.

[21] Norajitra, P., et.al.: He-cooled Divertor development for DEMO, Fusion Engineering and Design, 82 (15-24), 2007, p.2740-2744.

[22] Ishii, M., Hibiki, T.: Thermo-Fluid dynamics of Two-phase flow, Springer, 2011.

[23] Gorbis, Z.R., Raffray, A.R., Abdou, M.A.: High Heat Flux removal by phase-change fluid and particulate flow, Fusion technology, 23, 1993, p.435-441.
[24] Inoue, A., et.al.: Two-dimensional impinging jet cooling of high heat flux surfaces in magnetic confinement fusion reactors, Fusion Engineering and Design, 28, 1995, p.81 89.

[25] Inoue, A., et.al.: Studies on a cooling of high heat flux surface in fusion reactor by impinging planar jet flow, Fusion Engineering and Design, 51-52, 2000, p.781-787.

[26] Rosenfeld, J. H., et.al.: Advances in porous media heat exchangers for fusion applications, Proceedings of the 19th Symposium on Fusion Technology,1996, p.487-490.

[27] Raffray, A.R., et.al.: Critical heat flux analysis and R\&D for the design of the ITER Divertor, Fusion Engineering and Design, 45 (4), 1999, p.377-407.

[28] Baxi, C.B.: Thermal hydraulics of water cooled Divertors, Fusion Engineering and Design, 56-57, 2001, p.195-198.

[29] Bournonville, Y., et.al.: Numerical simulation of swirl-tube cooling concept, application to the ITER project, Fusion Engineering and Design, 84 (2-6), 2009, p.501-504.

[30] Suzuki, S., et.al.: Development of the plasma facing components in Japan for ITER, Fusion Engineering and Design, 87 (5-6), 2012, p.845-852.

[31] Gavila, P., et.al.: High heat flux testing of mock-ups for a full tungsten ITER Divertor, Fusion Engineering and Design, 86 (9-11), 2011, p.1652-1655.

[32] Cattadori, G., et.al.: Hypervapotron Technique in Subcooled Flow Boiling CHF. Experimental Thermal and Fluid Science, 7, 1993, p. $230-240$.

[33] Milnes, J.: Computational Modelling of the Hypervapotron Cooling Technique for Nuclear Fusion Applications, $\mathrm{PhD}$ thesis, 2010.

[34] Wang, Z., Song, Y., Huang, S.: Design of the Hypervapotron module for the EAST device, Fusion Engineering and Design, 87 (5-6), 2012, p.868-871.

[35] Smid, I., et.al.: Comparison between various thermal hydraulic tube concepts for the ITER divertor, Proceedings of the 19th Symposium on Fusion Technology, Lisbon, Portugal, 1996, p.263-266.

[36] Ezato, K., et.al.: Critical heat flux testing on screw cooling tube made of RAFM-steel F82H for Divertor application, Fusion Engineering and Design, 75-79, 2005, p.313-318.

[37] Ezato, K., et.al.: Thermal fatigue experiment of screw cooling tube under one-sided heating condition, Journal of Nuclear Materials, 329-333, 2004, p.820-824. 